\title{
El Fort Farell segons Francesc Maspons
}

\author{
Joan Armangué i Herrero \\ Universitat de Càller (Sardenya, Itàlia) \\ jarmangue@libero.it
}

RESUM

Tant la versió de «Lo Fort Farell» de Francesc Maspons com les que la seguiren, més que no pas en llegenda consisteixen en un seguit d'anècdotes atribuïdes a l'heroi, tal com haurien pogut ser atribuïdes a qualsevol altre gegant bo. O a qualsevol home fort, veritablement fort. Recorden en efecte les aventures d'El Fuerte de Ocháran, d'Antonio de Trueba, o del popular Xic de Vaquerisses; i les gestes de Samsó, les proves d'Hèrcules, les mesures de Goliat $i$ altres gegants de l'Antic Testament. A través del seu personal mètode historicocomparatiu, Maspons vol analitzar científicament quin lloc ocupa la nostra llegenda dins del llegendari indoeuropeu. I li sembla trobar-ne els orígens entre els pobles del Nord o germànics, tot deixant de banda el llegat romà i fins i tot bíblic. Mentre Maspons escrivia tot això, però, encara no havia estat difosa a Europa l'Epopeia de Gilgameix, heroi que es remunta al III mil-lenni aC i que no deixa de personificar... precedents llegendes.

PARAUles CLAU

gegant; heroi; llegendes indoeuropees; llegendes bíbliques; epopeia 


\begin{abstract}
Rather than a legend, both the version of "Lo Fort Farell" by Francesc Maspons and the ones that followed it consist of a series of anecdotes attributed to the hero that could just as well have been attributed to any other good giant or any strong man. They indeed remind us of the adventures of El Fuerte de Ocháran by Antonio de Trueba or of the popular Xic de Vaquerisses. They also bring to mind Samson's feats, the labours of Hercules, Goliath's measures and other giants from the Old Testament. Through his own comparative historical method, Maspons scientifically analyses where our legend stands within the Indo-European canon and seems to find its origins in Scandinavian or Germanic tribes rather than in the Roman and even the Biblical traditions. When Maspons wrote about all this, however, Euope had yet to become familiar with the Epic of Gilgamesh, a tale that dates back to the III millennium BC and whose hero embodies aspects of earlier legends.
\end{abstract}

\title{
KEYWORDS
}

giant; hero; Indo-European legends; Biblical legends; Epic poem

REBUT: 25/O8/20I9 | ACCEPTAT: 03/03/2020 


\section{L'obra}

Francesc Maspons va incloure l'any I876 la llegenda intitulada «Lo Fort Farell» a les seves Tradicions de Vallès. ${ }^{I}$ Abans d'ell havia difós la llegenda del nostre heroi, però en un àmbit molt local, Climent Cuspinera, a la Guía-Cicerone del viajero ó bañista en Caldas de Montbuy (I873: II8-I24). Empès pel seu afany d'exhaustivitat, Maspons transcriu en nota, al marge de la seva obra personal, dos fragments d'aquesta guia: la lluita entre el Farell i el Negre de Barcelona, ${ }^{2}$ anècdota que, malgrat les coincidències temàtiques i textuals amb la versió de Maspons, segueix altres fonts; i el llançament del pi o bastó per damunt de la muralla, que probablement ell no havia sentit de persona. «Ja que hem parlat del llibre del senyor Cuspinera, devem fer constar per sempre, que sols hem posat en la nostra obra les tradicions que personalment hem recollit de veu del poble», escriu abans de concloure la nota. ${ }^{3}$

Apel-les Mestres (I895), en canvi, entre les seves Tradicions, gairebé només recorda «El Fort Farell» (n. LXVI del recull) per tal de repetir, després d'haver-ho fet constar honestament, allò que havia escrit Maspons vint anys abans, afegint-hi tan sols petitíssimes variants degudes al fet que segueix ell també una font diferent: la memòria pròpia, d'on extreu tres «anècdotes» que «quasi paraula per paraula tal com les recordo jo les té ell transcrites».4 Ara bé, ens llega una contarella —fonamental, d'altra banda- que Maspons no havia recollit a les Tradicions del Vallès: el llançament del bastó del Farell, és a dir, un pi, per damunt de les muralles de Barcelona.

L'any abans de les Tradicions del Vallès, el I875, la germana de Francesc Maspons, Maria de Bell-lloc (pseudònim de Pilar Maspons), havia inclòs «Lo Farell» al seu recull de Narracions y llegendas, que, presentades als Jocs Florals, obtingueren un accèssit. ${ }^{5}$ Era president del Consistori dels Jocs Florals d'aquell I875 el senyor Francesc Pelai Briz, cunyat de Francesc Maspons i de la guanyadora (Armangué 2004: 23). De qualsevol manera, aquesta llegenda (Bell-lloc 2004: 97-IO2), malgrat el títol, no té cap relació amb la que ens ocupa, des del moment que consigna

I Nosaltres no llegirem, però, Maspons (I876) sinó la segona edició (Maspons I952: I7-25), «amb ortografia i sistema gramatical regularitzats», tal com consta en el pròleg a càrrec del fill de Francesc Maspons i Labrós (el nostre folklorista), Francesc Maspons i Anglasell. Com que text i notes ocupen poc espai, normalment no indicarem la pàgina d'on extraiem les nostres citacions, fàcilment localitzables.

2 En relació amb aquests personatges i altres gegants, vegeu Grau (I995: s. v. «Gegant»).

3 Tot adreçant una lleugera crítica envers Cuspinera, Maspons aclareix encara que «no van inserides en el present llibre les [tradicions] que amb el títol de "Las ligas de las seis doncellas" porta don Víctor Balaguer en la seva obra Una espedicion á S. Miguel del Fay i que copia el dit senyor Cuspinera en son referit llibre».

4 «Lo Fort Farell» va ser acollit, encara, al recull de Maria Bell-lloc Costums y tradicions del Vallés, premiat l'any I882 al Segon Certamen Artístic i Literari del Casino de Granollers (Oriol-Samper 20II: 553). Maspons havia estat president del Primer Certamen, l'any i88I. Són interessants les informacions de caràcter etnològic a la veu «Farell» del DCVB: «2. Nom d'un gegant llegendari que diuen que habitava a Catalunya, nadiu de Caldes de Montbui, i que feia grans proeses de força. Sembla un Farell: es diu d'una criatura que parla o acciona com una persona gran (Pineda). 3. Nom que vulgarment es dóna al vent, perquè hi ha la creença que és produït pel buf del gegant Farell en irritar-se.»

5 Citem a partir de la nostra edició de les Tradicions, també amb ortografia normalitzada (Mestres 2009: 67-69). 
records cronològicament precedents (un prequel) a les gestes del Fort Farell. Si ara ens interessa, a més del títol, és perquè hi recorda la fundació de can Farell, mas situat al cim més alt de la muntanya del Farell, rere Caldes de Montbui. ${ }^{6}$ Al temps en què Maria de Bell-lloc escrivia, la masia era «quasi arruïnada, cobertes d'heura ses parets i son sòl encatifat de bardisses. Tothom mira aquelles ruïnes amb certa superstició i fins molts per res del món s'hi atansarien» (Bell-lloc 2004: 97). Un escenari predisposat a acollir noves fantasies, un terreny ben fèrtil per al llegendari personal de Francesc Maspons. ${ }^{7}$

\section{La llegenda}

Més que no pas això, però, ens afanyem a cridar l'atenció sobre el paràgraf amb què Mestres presenta l'heroi i l'estructura de la seva llegenda: «El personatge no té una llegenda completa, arrodonida, les anècdotes aillades i incoherents que d'ell es conten són prou per dibuixar-ne la colossal silueta en la qual encarnà la Catalunya oriental l'home fort, el gegant, l'Hèrcules, el Samsó que necessita la imaginació de tot poble» (Mestres 2009: 67).

En efecte, «Lo Fort Farell» de Maspons i totes les versions que la seguiren, més que no pas en una llegenda, consisteix en un seguit d'anècdotes (per seguir amb el llenguatge de Mestres, amb el qual coincidim), que li són atribuïdes tal com haurien pogut ser atribuïdes a qualsevol altre gegant bo. O a qualsevol home fort, si volem; veritablement fort.

De manera molt oportuna, el mateix Maspons resumirà la vida de l'heroi de Caldes en un opuscle, cinc anys posterior a les Tradicions, dedicat a Lo Vallés:

De aquella época es també la tradició del Fort Farell, home alt i gros, de geni no obstant pacifich, com sos consemblants, que quan volia eixir á passeig anava al bosch y de un sol cop de ma arrancava un pí; qu'estimbava trossos de montanya; que desafiava en forsa y a menjar als homes més valents; senyalava lo camí alsant bous, gleva y arada, y tenint set posava un peu al cim de una alta montanya y l'altre en una altre y s'ajupia al fons de la vall á beurer aygua (Maspons I88I: 2I).

Amb això n'hi hauria prou per fer-se'n una idea. Naturalment nosaltres, volent analitzar amb atenció la llegenda, preferim esquematitzar-ne amb més rigor l'estructura, tot aillant cadascuna de les anècdotes i, en definitiva, desmuntant allò que amb tanta cura Maspons literàriament havia muntat. L'esquema narratiu de «Lo Fort Farell» és el següent:

\footnotetext{
6 A la seva introducció geogràfica, també F. Maspons recorda amb molta tendresa la masia, d'on fa propietaris «els rics Farells», dels quals el cim pren el nom i no pas el contrari. En un altre lloc (Maspons I887) assegurarà que havia recollit aquesta llegenda «a la Casa de les Serps, prop de la muntanya del Farell» (Oriol-Samper 20II: 553).

7 Maspons descriu amb les següents paraules les pedres de can Farell, des d'una perspectiva externa, com si a l'interior no hagués de ser tot ruïna: «L'ampla estesa de la teulada que mostra, els grossos corrals bons per a guardar a cents els caps de bestiar, els cellers amb ses portes foranes per a les tines [...], la capelleta, l'ampli barri, les corts i porxos tots grans i tots espaiosos, denoten bé que és grossa pagesia.» No li consta que s'hi hagin aturat les activitats agrícoles: «[...] en les quals [tines de can Farell], quan ve el temps de la verema, tenen de fer descans llargs rengs d'empicarolats matxos».
} 
I. Context geogràfic i humà:

I.a. Introducció geogràfica al Vallès, la masia de can Farell;

r.b. El Fort Farell: arrenca pins per fer-se'n bastons i alça barres de ferro;

2. Indica una direcció tot allargant el braç i aixecant l'arada i els bous;

3. A Barcelona:

3.a. Àpat de rivalitat entre el Fort Farell i un negre fort;

3.b. La lluita entre els dos titans;

4. Eixarrancat entre dues muntanyes llunyanes, abaixa el cap i beu l'aigua del Congost;

5. Ruïna de can Farell.

Maspons no recorda aquí, però, el passatge del famós llançament del pi per damunt de les muralles de Barcelona. Cuspinera (I873) l'havia recollit a la seva Guía de Caldes, però probablement Maspons no havia tingut ocasió de sentir-lo personalment de boca dels seus informadors, de manera que no l'inclou.

\section{El mètode historicocomparatiu}

És ben conegut el rigor amb el qual Francesc Maspons anotava els seus reculls de llegendes, les memòries de les seves excursions, les descripcions geogràfiques, i fins geològiques, del Vallès. Des d'un punt de vista etnològic, no cal dir que resulten molt més interessants per a l'estudiós d'etnopoètica aquestes erudites notes que no pas, ben sovint, el document folklòric que se'ns presenta. Concretament, a «Lo Fort Farell» el text i les notes ocupen aproximadament el mateix espai. Però aquí ens concentrarem en el ritme de les informacions que apareixen en nota, tot deixant de banda l'ordre narratiu, que ha de ser considerat un espai exclusiu per al plaer de la lectura serena.

D'aquest rigor, Maspons n'hauria dit, potser, «mètode científic» des del moment que analitza amb neguit el lloc que ocupen les nostres llegendes dins del llegendari indoeuropeu, tot seguint, de bo de bo, el «mètode historicocomparatiu» aplicat sobretot en filologia pels germans Grimm, mètode que ell mateix introduïa a Catalunya, on en fou l'únic representant durant el període romàntic (de fet, de la maduració romàntica), ${ }^{8}$ dins del qual va dur a terme els seus estudis i va endegar les seves publicacions (Samper 2OI7: 2I).

L'aparat de notes relatiu a «Lo Fort Farell» consta de quatre anotacions: la primera no té relació amb el Fort, des del moment que narra una sèrie de llegendes relacionades amb la Majestat de Caldes de Montbui —interessants sens dubte en una altra recerca diferent de la que ens ocupa; a més, la menció d'aquest crucifix en el text serveix tan sols per localitzar geogràficament la muntanya del Farell: «Detrás meteix de la termal vila de Caldes, la de la famosa Majestat, i del renomenat santuari de la Verge el Remei, s'aixeca, espadada i dreta, la muntanya dita del Farell.» La quarta nota és d'una sola ratlla.

Serà, doncs, a les notes 2 i 3 i en una sèrie de paràgrafs que fan el paper de nota conclusiva, sense numerar, on el folklorista bastirà una complexa xarxa de referències a altres llegendes nostrades però, sobretot, a reculls llegendaris de remotes terres i de temps allunyats per tal d'acabar concloent que el Fort Farell és deutor dels pobles del nord. I d'això es tracta: analitzarem a partir d'aquí aquestes refe-

8 Traiem l'expressió de Temporal (I998: 32). 
rències, seguint el seu ordre d'aparició a les notes —ordre i hipòtesi que haurien de ser prou convincents, segons l'autor, però per a nosaltres no ho seran.

D'aquesta manera, la primera afirmació historicocomparativa de Francesc Maspons és la següent, ben senzilla, elemental: «La tradició de l'home fort i valent, com el Samsó de la Sagrada Escriptura, es troba en tots els pobles.» Ens ho prendrem a la lletra. Posa al mateix nivell, doncs, Fort Farell i Samsó, però de cap dels dos no en diu gegant. A nosaltres, però, ens interessa parlar-ne.

\section{El gegantisme a la Bíblia, Goliat}

Segons la Bíblia, abans del Diluvi Universal les terres de Canaà eren habitades per una població de gegants, els Nefilim, els pecats dels quals van provocar la dràstica decisió de Jahvè: calia exterminar l'home de la terra, tot estalviant-ne el patriarca Noè i la seva família. Ara bé, uns quants d'aquests arcaics gegants, antics herois de l'èpica semítica, van sobreviure al Diluvi —o bé ressorgiren del fang—, tot donant lloc a l'estirp dels Nefaïm, que, normalment, representen l'encarnació de les velles forces del Mal: eren descendents de pecadors, Noè no ho era pas. Es tractava, en definitiva, de guerrers filisteus d'enormes dimensions, entre els quals destaca el nom de Goliat, atribuit a diversos militars que lluiten contra els jueus, i que acaben perdent la vida durant els combats (Moya I996: I2I).

El nostre Goliat, és a dir, Goliat de Got, mesurava sis braços i un pam (aproximadament tres metres). Era, evidentment, un descendent dels Nefaïm, com tants altres gegants. I, a sobre, guerrer filisteu (I Samuel I7, 4-7). Això, com podem imaginar-nos, semblava del tot natural, fins tradicional, entre els eventuals lectors de la Bíblia als temps de la redacció d'aquest passatge. Resultava senzillament versemblant: nefilim, en llengua hebraica, significa precisament 'gegant', 'tità'.

Pel que fa a aquest episodi, ens interessa anticipar un aspecte en què més endavant aprofundirem: ens referim al bastó de David; el gegant no en duia. El Primer llibre de Samuel dedica tot el capítol I7 al gegant Goliat i a la seva lluita contra David. Convé tenir en compte que David, que havia renunciat a l'armadura, no duia tampoc armes: no ho eren ni la fona ni el bastó, eines de treball pròpies dels pastors. El filisteu li demana: «Que sóc potser un gos, que véns contra mi amb bastons?» (I Samuel, I7, 43); més endavant, al v. 50, Samuel insisteix que David «no duia cap arma a les mans». Amb això pretenem desmuntar la teoria segons la qual el bastó dels gegants de llegenda i de rondalla «pertany a la iconografia de l'arma primitiva» (Moya I996: II9-I20).

\section{Samsó}

Aleshores, Samsó era un gegant? Goliat ha estat molt ben mesurat al Primer llibre de Samuel. També el bon Samsó? No pas. L'armadura de Goliat pesa 5.00o sicles (entre 50 i $65 \mathrm{~kg}$ ) i la punta metàl-lica de la seva llança, 600 (entre 7 i 8 kg). Què en sabem, d'aquestes dades referides a Samsó? El text bíblic no en diu res. Sembla més aviat que ens trobem de debò davant d'un campió, d'aquell «home fort i valent» de Francesc Maspons, el qual emprava aquesta expressió per referir-se al seu Fort Farell. El Farell mai no es beneficia d'un gegantisme explícit: el lector ha de deduir-lo a través de certs episodis. Provarem de fer el mateix amb Samsó.

Dir (o creure, però això de fet ja és una altra cosa); dir que Samsó era un gegant seria com fer-lo fill de Nefaïm, els titans ressorgits del fang, descendents dels Nefi- 
lim prediluvians, els pecadors condemnats per Jahvè, portadors del Mal i, tal com dèiem per amunt, sovint encarnats en cossos de guerrers filisteus. I els filisteus, en temps de Samsó, eren els dominadors d'Israel i Judà, eren l'enemic. Samsó, en canvi, pertanyia al poble de Dan, un dels fills de Jacob, fundadors de les dotze tribus establertes a Canaà. Era, doncs, semita, i la seva èpica matança de filisteus li va fer merèixer el títol de Jutge d'Israel, és a dir, de messies (provisional, malgrat tot).

No era un gegant. Aturem-nos, però, a analitzar el seu esquema biogràfic i el seguit de les seves proeses, tot llegint el Llibre dels Jutges (cap. I3-I6).

I. Naixement miraculós. Samsó és fill d'una dona estèril, com tants altres personatges de l'Antic Testament i fins del Nou (sant Joan Baptista);

2. Mata un lleó només amb les mans (com el babilonès Nimrod i el grec Hèrcules), de la carcassa del qual extraurà més endavant mel. La seva endevinalla adreçada als filisteus se'ls fa clara gràcies a la traïció de la seva muller, que ni sap contenir la curiositat ni, en acabat, la llengua. Una dona, doncs, l'enganya per primer cop;

3. Venjança contra els filisteus;

3.a. Imbuït de l'Esperit del Senyor, mata trenta filisteus;

3.b. Caça trenta xacals i, lligant-los hàbilment les cues i prenent-los foc, incendia els camps dels filisteus;

3.c. Imbuït altre cop de l'Esperit del Senyor, mata mil filisteus amb una barra (mandíbula) d'ase;

4. Assedegat, demana aigua al Senyor, que li obre una font en una roca en forma de morter. Ell hi beu;

5. Arrenca la porta de la ciutat de Gaza, amb les reixes i tot, se la carrega a l'esquena i la duu fins a Hebron (7o km en línia d'aire);

6. Traïció de Dalila i mort de Samsó, el qual, al darrer episodi de Jutges, fa caure el temple damunt de 3.000 filisteus.

No cal ser gaire espavilat per adonar-se que tot plegat representa una llista de llegendes precedents, independents l'una de l'altra i no necessàriament referides en origen al mateix personatge. En efecte, els historiadors de la Bíblia no dubten a assegurar que el Llibre dels Jutges és un recull d'aquelles anècdotes que dèiem, de llegendes i tradicions de diversa procedència i escampades per tot el territori. El redactor, probablement entre els segles $\mathrm{x}$ i viii aC, segueix fins i tot dos reculls diferents de dades tradicionals. Convé tenir en compte que, un cop escrita la versió definitiva, la que coneixem, la bíblica, i tal com passa també ara entre els recol·lectors i difusors d'etnotextos, la llegenda quedà ben fixada en la forma, duradora, generalitzada i... fossilitzada; esdevingué un material ben poc versàtil. Així i tot, el record de les seves gestes es consolidà i projectà vers el futur.

Per tal d'avaluar les forces i mesures de Samsó, convé eliminar els tres episodis en els quals el Senyor, de manera espontània o bé invocat pel protagonista, li insufla el seu Esperit (punts 3.a, 3.c i desenllaç del 6). Aquesta energia, evidentment, és d'origen diví i, per tant, no té límits ni nosaltres res a dir-hi.

Més problemàtiques se'ns presenten aquelles aventures que poden passar per versemblants, però que són altament improbables (punts 2 i 3.b), per exemple matar un lleó amb les mans nues i caçar en poca estona trenta xacals. Sembla que els exegetes tendeixin, en aquests casos, a minimitzar la dificultat de les empreses 
heroiques. ${ }^{9}$ Són com qui diu coses que, en certs ambients geogràfics, no són del tot impossibles. Pel que fa al lleó, el comentarista que seguim escriu: «Els lleons palestins, desapareguts a l'edat mitjana, no eren tan grossos ni tan forts com els africans, de manera que, sense necessitat d'un miracle, un home robust els podia matar» (Jutges, I4,8, nota). També l'episodi de la cacera dels trenta xacals, que «encara avui en dia viuen en grup a Palestina i poden ser fàcilment capturats» (Jutges, I5,4, nota), no sembla gaire desenraonat. L'important és, en definitiva, en els casos aparentment deutors del paganisme, eliminar tant la necessitat d'un miracle com l'afiliació a una llegenda.

Tornem a trobar-nos davant l'«home fort i valent» de Francesc Maspons. Com qui diu un home comú però robust, tal com se l'imagina Apel-les Mestres: «Segons el ja esmentat Sr. Maspons i Labròs [...], la casa del Farell existeix encara en el Vallès, cosa que podria fer suposar que realment hagués existit un Farell extraordinàriament forçut al qual la imaginació popular hagués agegantat i convertit en heroi de llegenda» (Mestres 2009: 68-69). No fora necessari consignar que, amb això del mètode historicocomparatiu, Apel-les Mestres no hi tenia la mà trencada. Ell, que havia llegit la versió de Maspons que estudiem, bé havia pogut adonar-se de l'erudit aparat de notes; sembla gairebé que vulgui contradir el mètode de Maspons, que se'n burli. I és que, per a ell —com per als exegetes de la Bíblia—, hi ha forces que són del tot naturals. No cal complicar allò que, segons el seu punt de vista, és senzill.

Però no hi ha res de senzill en el món bíblic; i és que Samsó, a més de fort, pot semblar-nos gegant si ens fixem en algunes de les seves gestes. Com que no sóc expert d'arquitectura religiosa de culte filisteu, no conec la distància aproximada entre les dues columnes mestres d'un temple, però jo no les hauria posades al centre de l'edifici, una al costat d'una altra, a I,5-2 m de distància entre elles. De manera que dono per suposat que per tocar-les totes dues alhora -i encara fer-les caure amb una genuflexió-, caldria tenir una amplada d'espatlles considerable, gegantina. Ara bé, arrencar (sense necessitat de l'ajut de l'Esperit) la porta de la muralla de Gaza i amb el reixat de ferro a l'esquena portar-ho tot plegat a Hebron i tornar de seguida (en total, I40 km), això sí que ho trobo una gesta per dur a terme la qual s'ha de ser gegantí; i plenament tradicional, perquè aquesta pura anècdota llegendària, que no té res a veure amb el context, pot tenir una sola i lleugera funció narrativa: treure el tema de la força bruta, ancestral i no miraculosa, que fa cremar d'enveja l'enemic, l'odi del qual confirmarà Samsó al lloc d'un sant hebreu (un Jutge) justicier dels no circumcisos, dels filisteus.

\section{Les armes dels gegants}

I, al capdavall, la prova més clara del seu gegantisme: quan després de la seva primera venjança contra els filisteus (n'ha matat trenta per tal de robar-los els vestits, imbuït de l'Esperit del Senyor), Samsó s'amaga a la cova d'Etam, han de fer-l'en sortir per tal de detenir-lo una colla de... tres mil homes. Com que no ho aconsegueixen, Samsó té l'oportunitat d'agredir els filisteus a Leki, de Judà, i amb l'ajut

9 Per qüestions de residència, no tenim accés a cap Bíblia catalana en paper. Remetem al text bíblic tot indicant com és habitual llibre, capítol i versicle, que gaudeixen d'una numeració cristiana comunament acceptada. Pel que fa als comentaris de l'exegeta, els traduïm de l'italià al català a partir de l'edició amb la qual treballem (Bibbia I995). 
de l'Esperit del Senyor matar-ne mil amb una... amb una barra d'ase. En aquest punt, una nota de l'exegeta ens aclareix: «En record de la massacre, el lloc passà a anomenar-se "turó de la Mandíbula", potser també per la seva conformació, semblant a una mandíbula» (Jutges, I5,I6, nota).

Ens trobem, ja es veu, davant d'una llegenda explicativa; és a dir, a partir d'un topònim o de la forma d'algun accident geogràfic (en aquest cas, les dues coses alhora), es constitueix la base per a una llegenda que justifiqui el nom del lloc. ${ }^{\text {Io }}$ Els hebreus del territori de Leki, llegint en aquell turó la silueta d'una mandíbula, devien imaginar que aquella arma, aquella enorme barra d'ase amb la qual Samsó havia occit mil homes, era talment com si s'hagués petrificat en aquell lloc... tot indicant les mesures de la veritable arma que hauria hagut d'emprar un gegant per a l'extermini de filisteus.

Tornant al Fort Farell, convé que aquí recordem que segons algunes versions l'heroi, fent camí a Caldes des de Barcelona, va decidir de quedar-se a dormir al ras a Collserola. La nit va ser molt freda, i el pobre Farell va morir-se congelat; o, millor, petrificat, des del moment que la seva silueta s'endevina fàcilment a la carena de Collserola (Amades I995: s. v. «Gegant de Collserola»).

Aquí no podem ocupar-nos, naturalment, de gegantisme en general ni de llegendes explicatives distants del fil que anem estirant. Pensem més aviat en les armes o les eines dels herois, perquè són les que ens demostren que ens trobem davant de gegants de debò. La barra d'ase emprada per Samsó es presenta encara ara enorme al «turó de la Mandíbula»; havia de ser-ho també el coltell de Rotllà, que tallà la muntanya del Puigcampana, a la Marina Baixa, per fer-hi una bretxa o Portell, tal com se'l coneix encara ara, que permetés al sol de pondre's més tard (Borja 2OII: 2OI); repetí aquesta mateixa operació «al Pirineu central, entre la vall de Gavarnia i la vall d'Ordesa», on «podem localitzar l'espectacular Bretxa de Rotlà, un impressionant esvoranc natural que s'obri [sic] als penya-segats del circ de Gavarnia, i que impacta pel paral-lelisme geològic evident —de tant com s'assembla— amb el Portell del Puigcampana» (Borja 20ıг: 205 i n. 9).

Ens fan riure, ara, els 600 sicles $(7-8 \mathrm{~kg})$ de la punta metàl-lica de la llança de Goliat.

Veurem més endavant el considerable embalum de la maça del «Frare valent», que la hi han de dur quinze homes. I si passem al món de la rondalla catalana, podem tenir en compte, per exemple, que «En Joan vint-i-un» demana al rei que li faci fer unes tenalles que pesin vint-i-un quintars (Amades I950: 232-237); ${ }^{\text {II }}$ "En Pere catorze» les vol de catorze pams (Alcover 2009: 355-380) ${ }^{\mathrm{I2}}$ —cadascú segons el numeral del seu sobrenom.

I el Fort Farell quin paper fa? Es defensa. Sabem en primer lloc que, segons la llegenda de Maspons, alça una barra de ferro com si fos un perpal o palanca; però, sobretot, ens il-lustra la mesura de les seves eines una ben oportuna història que Apel-les Mestres consigna a les seves Llegendes del Montseny, al punt dedicat a «El magall del Fort Farell».

Io Els diferents tipus de relat de caràcter explicatiu (llegenda, contarella i tradició) són molt ben analitzats per Oriol (2OII).

II «Explicada per Caterina Agulló, de Ciutat de Mallorca, el I922». Remet també a «Alcover, VIII, 54»; vegeu l'edició crítica de l'Aplec de rondaies (Alcover 2009: 355-380).

I2 Per a la localització d'aquesta rondalla en la formalització de les rondalles meravelloses (o la «Morfologia de la rondalla», segons Propp), vegeu Temporal (I998: 45I-452). 
Un vell de Viladrau, que fa poc va venir a Barcelona i al qual varen fer visitar el Museu Arqueològic, conta amb el més absolut convenciment que allí hi va veure «el magall del Fort Farell, que és una aïna per demés salvatge. Vaia si és aquell magall!... Amb aqueixa aïna arrencava el Farell els brucs per a fer carbó de rabassó. I per això el carbó de rabassó mai més ha pagat dret» (Mestres 2004: II7).

Ja ho deia Francesc Maspons: «És grossa pagesia.»

\section{El Fuerte de Ocháran}

Hem de reconèixer, però, que Maspons no pretén d'emparentar el Fort Farell amb el Samsó de les Santes Escriptures, des del moment que proposa aquest nom com qui diu de passada, com si aquest antropònim fos talment un adjectiu, un samsó, un dels samsons com aquest, que «es troba en tots els pobles».

Com a primer exemple d'home fort universal, Maspons no ha de sortir encara de la península Ibèrica. Continua en nota:

A les provincies Basques tenen una tradició bastant pareguda a la del nostre Farell [...], que realitza proeses ben bé pariones de les del nostre heroi [...]. Allí és «El Fuerte de Ocharán» (Maspons: I950: 22-23, n. 2).

Es refereix a El Fuerte de Ocháran (sic; en basc, Otxaran), llegenda recollida al volum d'Antonio de Trueba, Capítulos de un libro (I864: 249-269). Tot seguit, Maspons resumeix l'anècdota del parell de bous, «entre altres coses, per fer ressaltar més la semblança d'un i altre». De fet, es tracta de l'única semblança en aquest llistat caòtic d'empreses, talment amb la mateixa estructura del Fort Farell i el Samsó del Llibre dels Jutges. O, tal com deia Apel-les Mestres (2009: 67), aquí tampoc «el personatge no té una llegenda completa, arrodonida, les anècdotes [són] aïllades i incoherents».

Algun comentarista diu que en el llibre de Trueba aquesta història, que és l'última (també del punt de vista biogràfic del protagonista), és la que va rebre més aplaudiment i difusió (Maspons I950: I2); de fet, és la nostra opinió que aquesta difusió l'havia ja obtinguda a la Península si es va atribuir aquesta anècdota a un contemporani del País Basc. Perquè, si Trueba no és un geni de la ficció i l'engany (cosa encomiable en literatura, però no pas en recerca etnopoètica); si no és un manipulador de la ingenuïtat lectora, l'històric Manuel de Haedo va ser allà l'equivalent del fantasiós Fort Farell, i alhora d'aquell «Farell extraordinàriament forçut [i històric] al qual la imaginació popular hagués agegantat i convertit en heroi de llegenda» (Mestres 2009: 68-69). La gesta del Fuerte de Otxaran és la següent:

[El Fuerte de Ocháran] se disponía á ir á casa á comer cuando apareció por allí un alguacil de la audiencia de Avellaneda que iba de parte del teniente á evacuar una cita [...] —Diga usted, buen hombre, le preguntó el alguacil, ¿dónde vive el Fuerte de Ocharan? Manuel tomó con la mano derecha el arado por junto á la reja, y levantándole en alto y apuntando con él hacia su casa, como quien apunta con una vara, contestó: - Aquella es su casa. Dicho se está que el asombrado alguacil no necesitó hacer más preguntas ni pasar de allí para evacuar la cita (Trueba I864: 267-268). 


\section{Els pobles del nord}

Canviant ara de territori, toca de cop i volta el torn dels pobles del nord. Ens hi haurem d'entretenir, perquè el tema s'ho mereix: Maspons cercarà Farells i gegants de debò en el folklore germànic.

Abans de continuar, però, convé que consolidem un punt de partença fonamental. Com a deixeble de Herder, Francesc Maspons creu que la cançó popular (ell hi afegeix la llegenda per primer cop a Catalunya) és com aquell que diu l'àngel de la guarda i de la companyia dels pobles, de llur caràcter, llur esperit i, naturalment, també de llur territori. I, en aquest sentit, el territori ha estat construït pels diversos pobles que s'hi han succeï:

Al trobarse un ab monuments d'edats passadas, de pobles desconeguts, de rassas tant antiguas, se li conmou l'ánima considerant la munió de civilisacions y pobles que s'han passat damunt nostre, pensant que hi ha cosas més durables que no pas tota la forsa del home, quasi del tot ignotas apesar de son gran saber y estudi (Maspons I882: 3).

Entre tots aquests pobles que han configurat el territori que Maspons admira, se'ns anirà fent evident a poc a poc, però de manera molt clara, que prefereix el germànic: i voldrà demostrar les seves raons com a bon deixeble, alhora, dels germans Grimm i el seu mètode comparatiu. Probablement amb ben poca informació teòrica més enllà de la que arriba d'aquests autors, el vallesà bastirà una ben articulada teoria que lliga territori, pàtria i pertinença indoeuropea. Vet aquí una mena de manifest programàtic, d'un tarannà decididament vuitcentista:

Si l'estudi de les tradicions pot servir per a conèixer el camí que han seguit els diferents pobles que s'han succeït en la marxa de la civilització i llur influència en el país que trepitjaren, podríem demostrar aquí la gran força dels del Nord quan en el poc temps que estigueren entre nosaltres, deixaren tan marcadament impresa sa petjada, que fins en allò que sembla més insignificant sempre se'ls troba (Maspons I950: 23).

Acceptant la cultura del nord (fonamentalment la cristiana dels francs), Maspons no només rebutja la cultura que empeny pel sud (l'islam de la península Ibèrica), sinó també el substrat romà (és a dir, el paganisme). El cristianisme esdevé, per tant, un nou element per al paisatge nacional i per a la fantasia llegendària.

Aquesta competència entre nord i sud crea al Principat un aiguabarreig, una mena de lluita entre moros i cristians que es reflecteix en la diferència etnològica entre les dues Catalunyes:

En els diferents estudis que hem tingut ocasió de fer sobre la tradició catalana, hem pogut observar que les tradicions més brillants i formoses es troben, gairebé sempre, més a la Vella Catalunya que no pas a la Nova, en què en lloc del franc fou l'exèrcit sarraí que per més temps va dominar. [...] La tradició germànica brilla pura en aquella. Podem ben bé dir-ho: hi ha tanta diferència entre la tradició del que fou Catalunya Nova i Catalunya Vella, que més no pugui ser-hi; i arriba a l'extrem, per punt general, que si alguna de les tradicions de la part alta o antiga ha traspassat son límit, per barrejarse amb l'element dominant en l'altra comarca, es vesteix completament a la faisó d'aqueixa, i fins canvia de naturalesa (Maspons I876: 52). 
I pel que fa al substrat romà:

Els boscos, en sa grandiositat i feresa, el poble romà no els coneixia, car bé sabem que a part de les ciutats que habitava, sols li eren conegudes les «vil.les», que habitades la major part de l'any per esclaus, eren encara properes a les gran vies; mes la terra hisarda endins, amb prou feines la coneixien. En canvi, els pobles de Nord, baixant de sos frondosos boscos, avesats a sentir enmig l'exuberància d'una prepotent naturalesa [...], tenien una munió de tradicions brillants i formoses (Maspons I952: 5I).

De bo de bo, el que aquí Maspons fa és interioritzar un paisatge forà, introduir-lo literàriament a Catalunya, assimilar-lo al propi imaginari. Amb dolça melangia, a Maspons no se li farà, doncs, gens estrany que els visigots empatitzessin de manera gairebé hipnòtica amb el nou territori conquerit:

Terra donchs de tants boscos, espessos, gemats y hermosos, cóm no devia agradar á aquells pobles del Nort, fills de las boscurias de la Germania? ¿qué be no devian trobars'hi y cóm no la devían omplir d'aquelles tradicions y esperit poètich qu'en si portavan? (Maspons I88I: I6).

Això l'empeny a fer-ne objecte d'un estudi que agermani els pobles català i germànic. Per molt que per a ell els «pobles del Nord» siguin tant els visigots com els francs, els germànics en general i els escandinaus, al capdavall expressarà amb paraules de mal presagi un gentilici aclaridor:

Si aquí pogués fer un estudi comparatiu d'eixa tradició [relativa a una dona d'aigua], diria qu'es indubtablement de origen Ariá (Maspons I88I: 20).

\section{Les sagues escandinaves}

Hem anat construint la poètica, la teoria folklòrica de Francesc Maspons a partir de tres diversos opuscles o llibretons escrits entre els anys I876 i I882. Ara bé, durant aquest mateix període, a l'hora d'aplicar aquesta teoria l'autor no se n'acaba de sortir del tot bé. Abans, però, amb un esquema semblant al de les notes de «Lo Fort Farell», vegem on col·loca al seu opuscle Lo Vallès el nostre Fort dins del llegendari germànic:

[Lo Fort Farell] indubtablement es fill dels Yotes o gegants dels pobles del Nort, que significavan las forsas sensibles de la naturalesa; germà de la joveneta geganta de las Sagas que, anant un dia á passeig, vejé un home que llaurava, y admirada agafá home, parell y arada y ho portá com una joguina en lo palmell de la má a sos pares, tradició que s’troba viventa encare en lo Rhin, castell de Niedeck [...]. Germá del «Valerós frare» en Dinamarca [...]; del Samsó de las sagradas escripturas; del Fuerte de Ocharan de las Províncies Bascongadas [...]; del Xich de Vacarissas de nostra muntanya de Sant Llorenç del Munt, émul del deu Thor de l'Edda en lo menjar, etc. (Maspons I88I: 2I).

Veiem, doncs, que tant aquí com a la nota 2 de «Lo Fort Farell», Francesc Maspons proposa com a fenòmens de paral-lelisme germanocatalà dos exemples que haurien de demostrar, de testimoniar una clara influència nord-sud en un llarg procés d'aculturament, si m'és llegut. El primer: 
Només cal obrir les sagues escandinaves per a trobar una noieta filla d'un gegant que anant un dia de passeig, veu un home que llaura, l'agafa amb el parell i l'arada, s'ho posa tot al palmell de la mà i ho porta a sa mare com si fos una joguina (Maspons I952: 23).

En un text de I88I, Maspons aclarirà la bibliografia d'on ha extret aquesta fantasia gegantina: «F. J. Kiefer, Llegendas y tradicions del Rhin, pág. I9, "La joguina de la geganta"».13 No podem saber, naturalment, en quina llengua degué llegir Maspons aquest text, difós per Europa en diverses llengües a partir de I867 (probablement en francès).

Però, més enllà de lluir la seva erudició personal (que no sembla de moment gaire, si només ha trobat a les sagues escandinaves aquest míser paral-lisme), Maspons no resulta gens convincent: fora de l'esment al parell de bous i l'arada tant en aquesta historieta com en les llegendes del Fort Farell i del Fuerte de Otxaran, no hi ha res més de comú. I per a nosaltres, sincerament, si alguna coincidència volguéssim trobar-hi, diríem que certament entre els tres relats una clara coincidència sí que hi és: la del metall de l'arada, necessàriament de ferro. Les llegendes, doncs, foren fixades tal com ens han arribat fins ara després de la difusió del neolític, quan va néixer l'arada amb bous domesticats (per primer cop a la Mesopotàmia post. 6.00o aC), i més concretament durant o després de l'edat del Ferro (post. xii aC a l'Europa mediterrània; post. ix aC a l'Europa septentrional). Això és tot.

\section{Els cants del nord}

I, per acabar, el darrer exemple germànic i forà en general:

També en els cants del Nord publicats per X. Marmier (París I842), es troba, en el del «Frare valent», de Dinamarca (pàg. I05) ${ }^{14}$ la tradició de l'home fort i valent, ja que havent vist el frare una quadrilla de lladres que anaven a saquejar son convent, es fa portar sa maça, que li tenen de dur quinze homes, ni un mes ni un menys, l'agafa amb sols dos dits, se'n va al bosc, troba la quadrilla, composta de dotze lladres tots armats, i, lluitant amb ells, a tots els mata (Maspons I952: 23).

Més que no pas l'habitual «home fort i valent», l'heroi sembla un dels nostres gegants definits a partir de la mesura de l'arma o estri, tal com hem vist més amunt. I precisament tal com hem vist, aquesta característica no és privativa dels herois del nord: trobàvem la gegantina barra d'ase en Samsó i el ciclòpic magall en el Farell.

Decididament, i deixant ben clar que no pretenem generalitzar la nostra opinió a tota l'obra de Francesc Maspons, en aquesta llegenda de «Lo Fort Farell», malgrat l'extens, incisiu i ben informat aparat de notes, Maspons no aconseguirà

I3 Es tracta de Die Sagen Des Rheinlandes (Kiefer I87I).

I4 Xavier Marmier, Chants populaires du Nord Islande (Marmier I842). Al recull de Semprevivas (Maspons I885), el nostre rondallaire va presentar dues traduccions al català de contes deguts al folklorista francès: «La Catedral del rey» (I885: 9-II) i «Lo vas de llágrimas» (I885: 37-38), tots dos a partir de «"L'arbre de Noel" per Marmier, París I873)» (I885: 9-II). En el seguit de traduccions que caracteritzen aquest llibretó hi predominen històries de les terres del nord: llegendes d'Irlanda, de Lorena, del Rhin... Pel que fa a aquestes darreres, convé recordar que l'escriptor F. J. Kiefer, que Maspons ja havia recordat en tractar sobre l'origen germànic de «Lo Fort Farell», era autor d'unes Llegendas y tradicions del Rhin (Kiefer I87I). 
de ser versemblant en la seva atribució d'orígens germànics a aquesta llegenda. I fins i tot m'atreviria a dir que, pel que fa al món de les llegendes, Maspons, més que no pas un erudit (que és el que vol i creu aparentar), sembla un bon lector, apassionat, del llegendari indoeuropeu: al cap i a la fi, en aquesta ocasió ha citat només dues lectures del folklore del nord. Però no es podia esperar gaire més de les primícies del mètode comparatiu en el llegendari català, del qual Maspons resta, de qualsevol manera, pioner.

\section{Del Xic de Vaquerisses a Thor}

Recordem-nos, a més, que a l'opuscle dedicat a Lo Vallés el nostre folklorista hi afegeix un altre èmul del Fort Farell, «el Xich de Vacarissas de nostra muntanya de Sant Llorenç del Munt» (Maspons I88I: 2I). En efecte, a les Llegendes del Vallès Maspons el considerava "company» del Fort Farell - Mestres, en canvi, «amic i rival» (Mestres 2009: 68): el Xic de Vaquerisses agafa una carreta plena de garbes, l'aixeca amb bous i tot i la retira del seu camí.

Efectivament, aquesta proesa és molt semblant a la del Fort Farell (però hi manca l'arada de ferro). I també l'altra que els fa beure aigua als rius tot recolzant els peus en muntanyes llunyanes i abaixant el cap.I5 En aquest sentit, és molt interessant i gràfica la imatge que ens en dona Maspons:

El Fort Farell, el Xic de Vaquerisses i els protagonistes de les tradicions semblants d'altres pobles, que amb un peu en una de les més altes muntanyes, la del Montseny per exemple, posen l'altre a la de la Neu o al Puigfred, ço és, als munts més elevats, mentre queden sota ses plantes les fèrtils i treballades valls, els cabalosos rius, els escabrosos rouredars i pinedes, o sia la naturalesa tota, són la grandiosa imatge de l'home avassallador de tota la terra, que la domina, la trepitja i la fa tota seva (Maspons I952: 24).

S'ha de ser molt gegant. Però nosaltres, sincerament, llegim en aquesta llarga metàfora una probable referència a la situació política a l'Europa del moment, arran de la diplomàcia prepotent de l'Alemanya unificada, que preanunciava els totalitarismes del segle xx. Tinguem sobretot en compte, per comprendre bé la simbologia del text, que Francesc Maspons, tal com hem vist al llarg d'aquest article, considerava d'origen germànic o arià la llegenda de «Lo Fort Farell», de manera que l'al-lusió sembla molt directa.

No podem, però, tancar aquest apartat sense consignar que també Samsó va patir una gran set després de la batalla contra els filisteus. El Senyor, invocat, li va obrir una font en una roca en forma de morter, i ell hi va beure: tot seguit, el seu esperit va reanimar-se i es va reprendre; és per això que aquell lloc va passar a anomenar-se En-ha-Core, que, segons el comentarista del verset, significa «La font d'aquell que invoca» (Jutges, I5,I9). És clar que ens trobem, de nou, davant d'una llegenda explicativa, de caràcter toponomàstic, com la dels «Alts de la mandíbula». Podria haver-hi altres coincidències entre aquestes dues històries? Potser sí, des del moment que si el topònim Ramat-Leki, referit al serrat en forma d'enorme

I5 Per tal de corregir la vaguetat amb què havia tractat més amunt el tema, Maspons se sent obligat a justificar-se en nota: «Imprès el text, hem tingut ocasió de localitzar més el punt on el Farell posà els peus per ajupir-se a beure aigua del Congost. L'un el posà al mateix Turó del Tagamanent, i l'altre al Puigfred, al Pla de la Garga» (Maspons I952: 24). 
barra d'ase a la regió de Leki, és traduït per «Alts de la mandíbula», probablement aquí la forma de morter de la roca no es refereix a la mesura de l'estri casolà o artesanal, sinó a una roca de grans dimensions, com s'esdevé amb la barra d'ase. En aquest cas, Samsó hauria begut de manera tan mítica com els nostres gegants tradicionals. Però aquest simpàtic detall no el coneixerem, naturalment, fins que aquesta font no sigui localitzada a Leki, on, diu l'inspirat autor de Jutges, «fins al dia d'avui es troba» (Jutges, I5,I9); és a dir, si més no fins a aquells segles X-viii aC.

Més avall, sempre en nota, Francesc Maspons explicarà encara una altra anècdota relativa al Xic:

La tradició del Xic de Vaquerisses [...] es conta també dient que anava un dia el Xic junt amb un company, quan es toparen amb una carreta de bous curulla de garbes, i que tot plegat el company veié desapareguda aquella, i el Xic fent un moviment de coll com si engolís alguna cosa, i que preguntant-li aquell què és el que feia, li respongué el Xic amb tota senzillesa que s'acabava d'empassar una busca; i era que s'havia dragat la carreta (Maspons I952: 23).

El tema de la gana dels gegants té molt interessat Maspons. El troba d'origen germànic i ens remet a les sagues escandinaves des del moment que, tal com hem vist més amunt, el Fort Farell és també «émul del deu Thor de l'Edda en lo menjar» (Maspons I88I: 2I).

El Fort Farell era, com el Xic de Vaquerisses, un bon menjaire. De fet, abans de la seva lluita física contra el Negre de Barcelona, s'estableix entre els dos titans un repte de caràcter psicològic, simbolitzat a la llegenda per un àpat pantagruèlic (i vet aquí un altre gegant afamat).

[El Negre de Barcelona] manà fer un dinar de tanta cosa que era impossible que no embafés amb la sola vista. Fins hi havia un bou sencer i féu aposta al Farell de qui se'l menjaria (Maspons I952: 2I).

L'aposta, és natural, la guanya l'heroi vallesà, que és un pou sense fons. Pel que fa al Xic de Vaquerisses (que aquí és anomenat Miquel), comentant l'anècdota segons la qual un dia es va menjar un carro de bous, Maspons se'ns enduu altre cop cap al nord:

S'assembla aquesta versió a una altra. [El Miquel de Vaquerisses] tenia ganes de menjar enciam, i se'n menjà set carretades, l'amaní amb set botes [sic] d'oli i set fanegues de sal (el déu Thor, de l'Edda, a casa del príncep dels gegants, Thrim, es menja un bou enter, vuit salmons i tots els plats que li presenten) (Maspons I952: 24).

De fet, el de Vaquerisses el supera: quan els seus amics baixen amb una escala per la seva gola per tal de treure-li una busca, una molèstia, hi troben... set batallons de soldats que hi juguen a pilota!

Ara bé, sincerament no sembla del tot necessari tirar cap als substrats germànics aportats pels francs durant la seva estada a la Marca Hispànica; no sembla necessari, dic, tirar cap al nord per trobar-hi gegants famolencs envers els quals les nostres llegendes estarien endeutades. La cultura ària no sembla essencial, i ara no fora gens oportú, per defensar aquesta obvietat, aportar un pesat aparat erudit (noteu la cacofonia, que ja espanta), en text o en nota. M'abelleix, però, de recordar una llegenda kenyana que vaig estudiar en un altre lloc (Armangué 20I6). 
El seu títol és Karithong'o, l'ogre, text que coneixem gràcies a una versió narrada per un membre de l'ètnia kikuyu, la més nombrosa de l'actual República, establerta al voltant del Mont Kenya, al centre del país. Karithong'o és, efectivament, un ogre, el més petit entre els que viuen en comunitat. La seva fam és insaciable fins al punt que, després d'haver-se menjat tots els seus enormes companys, es menja ell mateix, i del seu cos només en queda una insòlita forma sense articulacions que recorda un tronc.

Això sí que és gana, un impuls natural, elemental, entorn del qual s'han construït tantes rondalles, no només nostres. Perquè, tal com és sabut, els déus i semidéus dels antics mites van passar a ser, amb el temps, els herois de les nostres llegendes, de les quals el poble ha recollit a les rondalles els protagonistes i els temes fonamentals que es troben a la base de la imaginació etnopoètica universal.I6 Abans, però, de passar a la rondallística, ens urgeix explicar una característica de Karithong'o:

La fisonomia d'aquest ésser maligne crida l'atenció sobretot perquè té un sol ull, i d'aquí és d'on procedeix el seu nom, Karithong'o, que en la llengua dels kikuyu, d'origen bantu, significa precisament 'el que té un sol ull'. I això ens porta, per força, cap a Polifem, el ciclop enemic d'Ulisses, que segresta l'heroi per tal de menjar-se'l, el tanca al seu refugi i acaba patint les conseqüències de la seva astuta fuga (llibre IX); tal com s'esdevé al conte kenyà, en el qual l'heroïna pateix la mateixa sort i guanya mèrit enganyant, al capdavall, el monstre.

Què volem dir, amb tot això? Que Francesc Maspons, fidel al mètode comparatiu indoeuropeista del temps, en aquest article no busca les fonts arcaiques de la llegenda, no té en compte el mite (només ha recordat com de passada i de manera adjectiva el bíblic Samsó). El seu viatge és massa moderat, no arriba (probablement perquè no pot arribar-hi) més enllà del nord d'Europa; i, pel que fa al temps, es tanca en una cronologia tan estreta que s'atura en l'edat mitjana, en el cristianisme que Carlemany introdueix a Catalunya, en les sagues escandinaves recollides els segles XII i XIII.

Té en compte el déu Thor, però deixa de banda el Polifem d'Ulisses: i això que aquest darrer el que menjava era carn humana.

\section{El bastó dels herois}

No hi ha dubte que un dels protagonistes de la història del Fort Farell és el seu bastó. Maspons només en parla just al punt d'encetar la llegenda:

[El Fort Farell era] home honrat i valent, i tan fornit i gros, que quan tenia d'emprendre algun llarg camí, no feia res més que anar-se'n al bosc, arrabassar de cop i volta un dels pins més grossos, esqueixar-li la brancada, i amb el tronc se n'anava tan lleuger com si a la mà dugués una palla (Maspons I952: I9).

Ja hem cridat més amunt l'atenció envers el fet que la versió de Maspons no recull la notable empresa que duu a terme el Fort en arribar a Barcelona. Ja la coneixíem perquè l'havia publicada anteriorment Climent Cuspinera (I873: II8-I24), i Maspons ara la recollia en nota. Preferim, doncs, reportar la versió d'Apel-les Mestres a Tradicions:

I6 Vegeu Oriol (20I2, sobretot § 2.2 «El mite»: 69); i Violant (I990: I7). 
Una vegada el Fort Farell vingué a Barcelona a veure unes festes, i com que per bastó portava un pi, els guardes del portals volgueren fer-li pagar l'entrada. El Farell s'hi resistí al-legant que cap ordre del rei manava que els bastons haguessin de pagar dret, ja que per a ell era bastó el pi que portava.

Que si és bastó o és arbre, que si és arbre o bastó, va armar-se tal rebombori entre els guardes i el Farell que aquest, per demostrar-los que entraria el bastó sense pagar, va tirar-lo dins de la ciutat per damunt de les muralles (Mestres 2009: 68; el cursiu és nostre).I7

Altres herois mítics duien bastó, sense ser necessàriament vells ni gegants. Per tal de no allunyar-nos dels temes tractats, recordem que David en duia, i això que era un xicotet adolescent (I Samuel, I7, 43): el bastó no era més que un estri propi de caminants i pastors (com la fona), no pas una arma, com ho era en canvi el garrot d'Hèrcules. Qualsevol interpretació simbòlica que vagi més enllà de la que estem a punt de proposar ens semblarà possible però agosarada, recargolada i innecessària (vegeu, per exemple, Moya I996: II9-I20). Per la seva forma fàl-lica, traduïm el bastó dels nostres herois i gegants com un símbol de virilitat i, per tant, de força (o de traça, en el cas de David), de victòria.

I, dins de la rondallística, en Joan de l'Ós ${ }^{18}$ El mateix Francesc Maspons, a Lo Rondallaire (20I0: 57-6I), ens explica que era un gegant que anava pel món, tot fent amistat amb altres homes fantàstics, un dels quals ara ens crida l'atenció:

Camina que caminaràs, veus aquí que va trobar-ne un home a dins d'un bosc, que a cada cop de mà n'arrencava un pi de la terra, cosa de la qual ell ne fou tan agradat que li digué si volia ésser el seu company i l'Arrencapins, que tal es deia, ne fou content $\mathrm{i}$ junts emprengueren via (Maspons 2OIO: 58).

Notem que té en comú amb el Fort Farell no pas el fet que camini amb bastó, sinó que, tots dos, els arbres, els arrenquen.

En una de les seves empreses, algunes de les quals recorden els dotze treballs d'Hèrcules, «En Pere Catorze», en una versió recollida per Mn. Alcover a Mallorca (en aquest cas, a Son Servera), el rei envia l'heroi mallorquí «amb un carro i un parei de bous an es comellar d'es lleons a dur una carretada de llenya, perquè no en tenim p'es fogó ni p'es forn» (Alcover 2009: 357); és a dir, que amb una mica de llenya ja n'hi hauria hagut prou. Un cop al comellar, en Pere Catorze comença «a taiar pins»,I9 i ho fa de la manera següent:

I7 Potser el record d'aquesta famosa anècdota del Fort Farell va condicionar la memòria o la fantasia del «vell de Viladrau, que fa poc va venir a Barcelona i al qual varen fer visitar el Museu Arqueològic», segons ens recordava Mestres a les Llegendes del Montseny (2004: II7). El bon ancià es mostrava convençut que, amb un ciclòpic magall, el Fort Farell arrencava brucs per fer-ne «carbó de rabassó. I per això — dedueix— el carbó de rabassó mai més ha pagat dret».

I8 Pel que fa a la tipologia de les rondalles pertinents al nostre article («Gegant», per exemple), vegeu Oriol-Pujol (2003).

I9 «En Joan vint-i-un», d'Amades (el qual ha tingut ben en compte la versió d'Alcover en escriure la seva), tot i que va a buscar llenya com en Pere i pels mateixos motius, no arrenca ni talla pins (Amades I950: 232-237). 
No se servia de cap destral. Abraonava un pi, li pegava espolsada i, ta-trac, aquell pi romput. I hala a un altre pi i li feia sa meteixa funció. I llavò a un altre, i lo meteix.

Què me'n direu? Ell al punt en tengué una estesa, de pins, que feia feredat (Alcover 2009: 358).

Notem que es tracta sempre de pins sense copa: el Fort Farell, un cop arrencat el pi, li esqueixa la brancada; en Pere Catorze, l'espolsa i trenca. No es tracta dels bastons florits de l'hagiografia popular.

L'exemple més immediat, elemental, de bastó florit el trobem al nostre pessebre, en mans de sant Josep. El fet que una estèril branca de fusta, un bastó, floreixi en néixer Jesús i el seu nou Regne, pot fer referència tant a una creença popular com a una interpretació del tot ortodoxa. Diu que sant Josep era vell i, per això, se'l creia estèril (fenomen que, naturalment, no és cert); el fet que, d'una manera o altra, li neixi un fill, el fa fèrtil als ulls dels pessebristes, que tradueixen l'esdeveniment amb un bastó florit. Però també pot ser un símbol de renaixença, de canvi de Regne, de pas del paganisme al cristianisme.

I, per acabar, el darrer exemple de bastó florit, el més universal. És sabut que la història de sant Cristòfol no és bíblica, sinó que es tracta d'una llegenda que circulà en temps antics i que fou recollida, entre nosaltres, a les Vides de sants rosselloneses (s. xiii). Tenim la imatge (com qui diu l'estampa) de sant Cristòfol que carrega Jesús per travessar un riu, i s'ajuda, a tall de bastó, amb una palmera florida. Ara bé, abans de Jesús la palmera era simplement un bastó estèril: «El bastó de Cristòfor reverdeix (ara per la intervenció del Déu cristià creador de l'univers) com a manifestació simbòlica d'un natural i prereligiós culte a la natura rediviva» (Moya I996: I22). Crist mateix ho havia anticipat al sant amb aquestes paraules: «Tu ferma lo teu bastó costat la tua cassa, y veyràs que al matí serà florit e granat» (citat per Moya I996: I20).

I ara, com a conclusió tant d'aquest apartat com de l'article, ens centrarem en els herois que tallen o arrenquen pins.

\section{Conclusió. De Gilgameix al Fort Farell}

Coneixem la sumèria Epopeia de Gilgameix gràcies a una versió escrita en caràcters cuneïformes damunt certes tauletes d'argila trobades el I853 a la biblioteca del rei assiri Assurbanipal (s. VII aC). Fins al I872 no se'n va reconèixer la gran importància que tenien. La publicació dels fragments antics i, al capdavall, de la versió més completa coneguda (la que també nosaltres coneixem) va ser molt lenta. Fragment i versió final es refereixen a les gestes de l'històric rei d'Uruk, a Sumer, fill d'un déu com tants d'altres, constructor de les muralles de la ciutat i viscut al tercer mil·lenni aC, abans que fos escrita la Bíblia i, naturalment, l'Ilíada i l'Odissea. Durant el segon mil-lenni aC, van començar a circular pel territori els primers textos escrits que recordaven l'heroi sumeri; aquests documents, com és habitual, recollien llegendes orals anteriors.

Francesc Maspons, per tant, no podia conèixer l'Epopeia. Però se'ns acut que no resulta del tot inútil (esperem, encara més, que pugui resultar constructiu) destacar dos episodis del cicle de Gilgameix.

Aquest tità lleugerament postdiluvià va deixar la seva terra per tal de travessar el desert i pujar fins al Líban o el sud de Pèrsia, cap a la Muntanya dels Cedres. El 
cedre és un arbre imponent que es distingeix, precisament, per la seva gran alçada i per la qualitat de la fusta, que mai no es corca. No és un pi, és un cedre. I la reconstrucció de les muralles d'Uruk necessitava, naturalment, molta fusta per a qualsevol activitat mural.

Doncs bé, un cop arribats ell i el seu company Enkidu al bosc — han hagut de superar proves molt perilloses, a l'abast només dels grans herois-, han de trobar-hi el desitjat Cedre: aquest, que al capdavall és un de sol entre els altres, «s'alçava davant de la muntanya amb tota la seva grandària, la seva ombra era magnífica, plena de repòs» (Sandars 200I: I03).20 Un cop localitzat, «Gilgameix va agafar amb la mà una destral i va abatre el Cedre» (Sandars 200I: IO5); en va tallar les branques i les va estendre al peu de la muntanya.

Gilgameix, en resum, talla arbres i els estén en gran quantitat (els cedres són veritablement més alts que no pas els pins), talment com havia fet en Joan de l'ós al comellar dels lleons (per cert, també Gilgmeix lluita contra lleons, com Samsó, Hèrcules i en Joan de l'Ós). No arrenca pins, els talla: però ens adonem de les seves mesures gegantines.

Volem amb tot això insinuar una certa filiació d'algunes llegendes de gegants, d'algunes rondalles catalanes amb el sumeri semidéu? No pas. Però hi evidenciem certs paral·lelismes. I el segon del qual volem parlar és el següent.

Abans de fer-se amics, Enkidu i Gilgameix eren acèrrims rivals. Quan els dos herois encara no es coneixien, Enkidu, en assabentar-se de l'existència i la força de Gilgameix, decideix de reptar-lo i a Uruk, la ciutat, proclama a crits: «Soc jo el més fort, he vingut a canviar l'ordre antic» (Sandars 200I: 92). La mecànica del repte entre els dos titans és gairebé idèntica a la del Fort Farell i el Negre de Barcelona. El poble els veu com dos rivals dignes l'un de l'altre. I vet aquí la descripció de la lluita:

De nit Gilgameix va alçar-se del llit i va anar cap a la casa. Llavors Enkidu en va sortir i va quedar-se enmig barrant el pas. Gilgameix va avançar potent i va trobar-lo a la porta. Va dur el peu endavant i [1'altre] va impedir que Gilgameix entrés a casa; i així va començar la lluita, que tots s'abraonaven l'un contra l'altre com dos braus. Van trencar les portes, les parets van tremolar: bufaven com bous abraçats. Gilgameix va plegar el genoll, el peu plantat a terra, i amb un sol cop Enkidu va caure (Sandars 200I: 93-94).

La victòria, doncs, va ser per a Gilgameix, el que havia tallat l'arbre, símbol fàllic com el bastó, símbol de força i de triomf, tal com dèiem en parlar més amunt del Fort Farell i dels herois nostrats, de llegenda o de rondalla.

La baralla entre el Fort Farell i el Negre de Barcelona no és, naturalment, tan èpica en la majoria de les versions. Encara més, resulta còmica. Ara bé, llegim la versió de Cuspinera, anterior com hem vist a la de Maspons, que descriu així la batalla:

L'autoritat militar [de Barcelona] tenia a son servei un negre de grossa força, que volent donar una prova de son invencible poder, demanà a son amo que el deixés lluitar amb el Farell [...]. El Farell acceptà. A l'hora assenyalada el baixaren a un pati, i desitjant humiliar el negre [...] es posà

20 No podent accedir a una versió catalana d'aquesta epopeia, traduïm el text al català a partir de la versió italiana de Sandars (200I). La nostra breu nota introductiva recull materials de la «Introduzione», a càrrec del curador. 
a la seva disposició perquè fes d'ell el que volgués. El negre, amb poca delicadesa, acceptà l'oferiment i es llençà furiós contra son adversari, agafant-lo pel cos amb totes dues mans, pensant-se esmicolar-lo; emperò per més forces que féu, ni tan sols pogué bellugar-lo una mica. Llavors, tot avergonyit, es posà a l'abritre del Farell. Aquest l'agafà, i mostrant-se generós, en lloc d'esclafar-lo com hauria pogut fer, s'acontentà amb llençar-lo d'un sol cop a la volada de la teulada, amb admiració de tothom (Cuspinera I873: 25).

I ara acabem. Nosaltres, entre el nostre heroi i el sumeri, hi veiem certs para1.lelismes. No convenia aturar-se cronològicament en l'edat mitjana dels germànics (tesi defensada per Maspons sense èxit) ni geogràficament en l'àmbit de les llengües indoeuropees. Però tot això, de fet, havia d'arribar encara: Maspons no tenia la informació que tenim ara i, a més, era el pioner a Catalunya dels estudis comparatius.

Així i tot, Francesc Maspons va deixar de banda un aspecte que ara, al segle xxi, podria semblar elemental: no deu ser que aquestes llegendes (derivades en acabat en rondalles), evolucionades a partir del mite, senzillament han existit sempre, si més no des del moment en què l'home - la humanitat - va saber pensar i expressar-se amb uns símbols que, construïts a partir del territori i la cultura, potser podrien ser universals? Perquè, si eren comunicables, vol dir que formaven part de l'imaginari comú de tots els pobles.

\section{Referències bibliogràfiques}

Alcover, Antoni Maria (2009): Aplec de rondaies mallorquines d'En Jordi des Racó. Edició a cura de Josep Grimalt amb la col-laboració de Jaume Guiscafrè. Mallorca: Moll.

AMADES, Joan (I950): Folklore de Catalunya. Rondallística. Barcelona: Selecta.

ARMANGuÉ, Joan (2004): «Presentació». Dins Maria de Bell-lloc: Llegendes. Barcelona: Publicacions de l'Abadia de Montserrat, p. 5-29.

- (20I6): «Particularitat i universalitat etnopoètica. La narrativa popular kenyana: coincidències, vincles i concomitàncies». eHumanista IVITRA núm. 9: IOO-II5 < http://www.ehumanista.ucsb.edu/ivitra/volumes/9> [data de consulta: maig de 2020].

Bell-LlOC, Maria de (2004): Llegendes. Barcelona: Publicacions de l'Abadia de Montserrat.

BibBiA (I995): La Bibbia concordata, IO v. Milà: Mondadori.

BORJA, Joan (2OII): «Llegenda i paisatge: sobre la Coltellada de Rotlà al Puigcampana». Dins Àngel VerGés; Jordi Colomer (eds.): Llegendes i paisatges dels Països Catalans. Banyoles: Centre d'Estudis Comarcals de Banyoles, p. I99-2I9.

CuspinerA, Climent (I873): Guía-Cicerone del viajero ó bañista en Caldas de Montbuy. Barcelona: Leopoldo Domenech.

GrAU, Jan (I995): Fabulari Amades. Barcelona: El Mèdol.

KIEFER, F.J. (I87I): Die Sagen Des Rheinlandes Von Basel Bis Rotterdam.

MARMIER, Xavier (I842): Chants populaires du Nord Islande: Danemark, Suèce, Norvege, Feroe, Finlande. Traduits en français et précédés d'une introduction. Charpentier. 
MASPONS, Francesc (I876): Tradicions del Vallès. Barcelona: Impremta La Renaixença.

— (I88I) [= I882]: «Lo Vallés». Extret de l'Anuari de l'Associació d'Excursions Catalana - I88I. Barcelona: Estampa de Jaume Jepús, I882.

— (I882) [= I883]: «De Mollet á Bigas». Extret de l'Anuari de l'Associació d'Excursions Catalana - I882. Barcelona: Estampa de Jaume Jepús, I883.

- (I885): Semprevivas. Barcelona: Llibreria de D. Alvar Verdaguer.

- (I887): «Excursió col-lectiva al Farell». Bulletí Mensual de l'Associació d'Excursions Catalana núm. IOO: 2-5; núm. IOI-IO2: I9-24.

- (I952): Tradicions del Vallès. Barcelona: Barcino.

— (20IO): Lo rondallaire. Edició a cura d'Albert Mestres. Valls: Cossetània.

Mestres, Apel-les (I895): Tradicions, recullidas y escritas per Apeles Mestres. Barcelona: Espasa y Companyía.

- (2004): Llegendes del Montseny. Edició a cura de Carme Rubio i M. Carme BerNAL. Barcelona: Publicacions de l'Abadia de Montserrat.

- (2009): Tradicions. Edició a cura de Joan Armangué. Valls: Cossetània.

ORIOL, Carme (2002): Introducció a l'etnopoètica. Teoria i formes del folklore. Valls: Cossetània.

— (2OII): «Literatura oral i territori; llegendes, contarelles i tradicions referides a lloc». Dins Àngel Vergés; Jordi Colomer (eds.): Llegendes i paisatges dels Països Catalans. Banyoles: Centre d'Estudis Comarcals de Banyoles, p. I3-2I.

Oriol, Carme; Josep M. Pujol (2003): Índex tipològic de la rondalla catalana. Barcelona: Centre de Promoció de la Cultura Popular i Tradicional Catalana.

OrIOL, Carme; Emili SAMPER (eds.) (2OII): Repertori biobibliogràfic de la literatura popular catalana: el cicle romàntic. Tarragona: Publicacions de la Universitat Rovira i Virgili.

- (20I7): Història de la literatura popular catalana. Alacant/Palma/Tarragona: Edicions de la Universitat Rovira i Virgili/Publicacions de la Universitat d'Alacant/Edicions de la Universitat de les Illes Balears.

SAMPER, Emili (2OI7): «El període romàntic: Els inicis de l'interès per la literatura popular a Catalunya». Dins Carme ORIOL; Emili SAMPER: Història de la literatura popular catalana. Alacant/Palma/Tarragona: Edicions de la Universitat Rovira i Virgili/Publicacions de la Universitat d'Alacant/Edicions de la Universitat de les Illes Balears, p. I5-6o.

SANDARS, N.K., (ed.) (200I): L'epopea di Gilgameš. «I Grandi classici della Fiaba», s.n. Milà: Fabbri Editori.

Temporal, Josep (I998): Galàxia Propp. Aspectes literaris i filosòfics de la rondalla meravellosa. Barcelona: Publicacions de l'Abadia de Montserrat.

Trueba, Antonio de (I864): Capítulos de un libro, sentidos y pensados viajando por las provincias vascongadas. Madrid: Centro General de Administración.

ViolAnt, Ramona (I990): La rondalla i la llegenda. Contribució a l'estudi de la literatura folklòrica catalana. Barcelona: Alta Fulla. 